\title{
Candidate Biomarkers in Children with Autism Spectrum Disorder: A Review of MRI Studies
}

\author{
Dongyun $\mathrm{Li}^{1} \cdot$ Hans-Otto Karnath ${ }^{2,3} \cdot \mathrm{Xiu} \mathrm{Xu}^{1}$
}

Received: 8 January 2017/ Accepted: 17 February 2017/Published online: 10 March 2017

(C) The Author(s) 2017. This article is published with open access at Springerlink.com

\begin{abstract}
Searching for effective biomarkers is one of the most challenging tasks in the research field of Autism Spectrum Disorder (ASD). Magnetic resonance imaging (MRI) provides a non-invasive and powerful tool for investigating changes in the structure, function, maturation, connectivity, and metabolism of the brain of children with ASD. Here, we review the more recent MRI studies in young children with ASD, aiming to provide candidate biomarkers for the diagnosis of childhood ASD. The review covers structural imaging methods, diffusion tensor imaging, resting-state functional MRI, and magnetic resonance spectroscopy. Future advances in neuroimaging techniques, as well as cross-disciplinary studies and largescale collaborations will be needed for an integrated approach linking neuroimaging, genetics, and phenotypic data to allow the discovery of new, effective biomarkers.
\end{abstract}

Keywords Autism spectrum disorder - Biomarker . Neuroimaging $\cdot$ Structural MRI $\cdot$ Diffusion tensor imaging $\cdot$ Resting-state functional MRI $\cdot$ Magnetic resonance spectroscopy $\cdot$ Children $\cdot$ Human

Xiu Xu

xuxiu@shmu.edu.cn

1 Division of Child Health Care, Children's Hospital of Fudan University, Shanghai 201102, China

2 Division of Neuropsychology, Center of Neurology, Hertie Institute of Clinical Brain Research, University of Tübingen, 72076 Tübingen, Germany

3 Department of Psychology, University of South Carolina, Columbia, SC 29208, USA

\section{Introduction}

Autism spectrum disorder (ASD) is a neurodevelopmental disorder that has a strong genetic basis, a heterogeneous etiology, and various clinical presentations. The core symptoms of ASD include: (1) deficits in social communication and social interaction, and (2) restricted, repetitive patterns of behavior, interests, or activities [1]. The prevalence of ASD has dramatically increased recently from 4 in 10000 to 1 in 68 children [2, 3]. Along with the soaring incidence of ASD, significant financial and emotional costs to the individuals and their families, as well as the numerous pressures on our medical, social, and political lives have been engendered [4]. Hence, determining the causes and making an accurate diagnosis as well as early and effective intervention seem crucial for society [5].

So far, the diagnosis of ASD and the selection criteria for clinical trials have been guided by the Diagnostic and Statistical Manual of Mental Disorders or behavioral diagnostic scales. The apparent disadvantage of symptombased criteria is that a similar symptom or phenotype may arise from diverse sets of biochemical processes, especially for disorders with numerous genetic or environmental factors like ASD [6]. In the past decade, searching for genetic biomarkers has been one of the hottest spots in ASD research. Numerous related genes have been reported including NRXN1, SHANK3, SHANK2, MECP2, SNC2A, CHD8, DYRKIA, POG2, GRIN2B, KATNAL2, NLGN3, NLGN4, CNTN4, CDH10, CDH9, and SEMA5A [7-17]. Unfortunately, the genetic underpinnings of ASD are neither simple nor consistent, considering that only 10\%-38\% of ASD cases have been reported with known genetic deficits [18-20]. Because of this heterogeneity and complexity, interest and efforts into searching for more biomarkers and quantifiable parameters are increasing in 
order to facilitate early and reliable diagnosis, as well as to subgroup patients sharing common pathophysiological underpinnings.

Magnetic resonance imaging (MRI), a non-invasive examination tool, has been widely applied to ASD populations to delineate the developmental trajectory of the brain. Major advances in structural and functional MRI techniques in the past decades have greatly enriched our understanding of neuropathological differences in ASD [19, 21, 22]. Generally, structural MRI has revealed ASD to be a disorder with general and regional brain enlargement, especially in the frontotemporal cortices, while functional MRI studies have highlighted diminished connectivity, especially between frontal-posterior regions [19, 21-25].

Here, we review recent MRI studies (since 2000) in young children with ASD, aiming to provide effective biomarkers for the diagnosis of childhood ASD. We focus on studies using structural imaging methods, structural connectivity analyses, diffusion tensor imaging (DTI), neurochemical or metabolic quantification methods, and magnetic resonance spectroscopy (MRS), as well as functional connectivity analyses with resting-state functional MRI (rs-fMRI). We do not consider task-based functional methods, since it is almost impossible to keep a young child awake and still during a functional scan. We place the emphasis on young ASD children because in adolescents and adults the altered brain structures and activities may merely reflect the social deprivation experience elicited by reduced social attention during childhood. Therefore, it is impossible to tell whether observed functional or structural differences are the cause or the result of ASD neuropathology. Another reason is based on brain plasticity. There is growing evidence that the first 3 years of life is a particularly critical developmental period for children with ASD [26, 27]. Thus, the earlier the abnormal neurodevelopmental trajectory (even in infants and toddlers) is identified, the better guided intervention strategies for ASD children can be achieved.

\section{Structural MRI}

Structural MRI analysis for neurodevelopmental disorders began to emerge in the 1990s when it focused on the neuroanatomical aspects of brain development. It has been used to measure the total brain volume and volumes of specific structures. Earlier studies used manual delineation for the gray (GM) and white matter (WM) to calculate the volumes of specific regions of interest (ROIs). With technical developments, it is now possible to use program codes to measure the volumes automatically, allowing large data sets to be processed more efficiently [28]. Based on the different analytic methods for structural data, structural MRI studies can be classified into voxel-based morphometry (VBM) and surface-based morphometry (SBM) [29]. VBM targets tissue density and usually focuses on relative GM concentration or volume, or regional volume differences of a certain tissue. SBM addresses topological features, like surface curvature and degree of folding [29, 30]. Notably, brain volume and surface curvature have been hypothesized to have dissociable developmental trajectories with, putatively, different genetic and neurodevelopmental bases [22, 31, 32]. Table 1 summarizes the findings of structural MRI studies in children.

\section{Cortex}

The most consistent observation regarding structural cortical changes in young ASD children versus controls is the increased total volume both in the cortical GM and WM [22, 30, 33, 34]. Increased GM volume (GMV) and WM volume (WMV) have been found in the frontal and temporal lobes and are less pronounced in the parietal and occipital lobes. For example, Carper et al. (2002) revealed increased frontal and temporal GMV and frontal and parietal WMV at young ages (2-4 years old) [35]. Sparks et al. (2002) likewise observed increased cerebral volumes in autistic children aged 4-6 years [36]. Akshoomoff et al. (2004) reported increased total brain volume (TBV), as well as significantly increased WMV and GMV in children of 4-6 years with low-functioning autism compared with high-functioning autism (HFA) [37]. Hazlett et al. (2006) investigated 51 younger autistic children and 25 typicallydeveloping controls (aged 18-35 months). They reported increased cerebral GMV and WMV in the brains of the autistic group [38]. In a group of 1.5-5 year-old autistic children, Schumann et al. (2010) found no changes in the occipital lobe but enlarged cerebral GMV in the frontal, temporal, and parietal lobes, as well as in the cingulate gyrus (located in the limbic lobe) [39]. Hazlett et al. (2011) compared the TBV of 6-month-old high-risk infants with autistic siblings with low-risk infants without autistic family members. They found no significant difference in the cerebrum or lateral ventricle volumes, consistent with the hypothesis that the brain enlargement might be a postnatal event, occurring at $\sim 12$ months of age [34]. However, Shen et al. (2013) identified excessive cerebrospinal fluid (CSF) over the frontal lobes at 6-9 months of age but no such difference at 12-15 and 18-24 months [40]. Recently, Gori et al. (2015) extracted features from GM, WM, and CSF measurements to classify autistic and control brains in 4-year-old males. They found that only GM features in different sub-regions showed up to $80 \%$ classification performance [41]. 


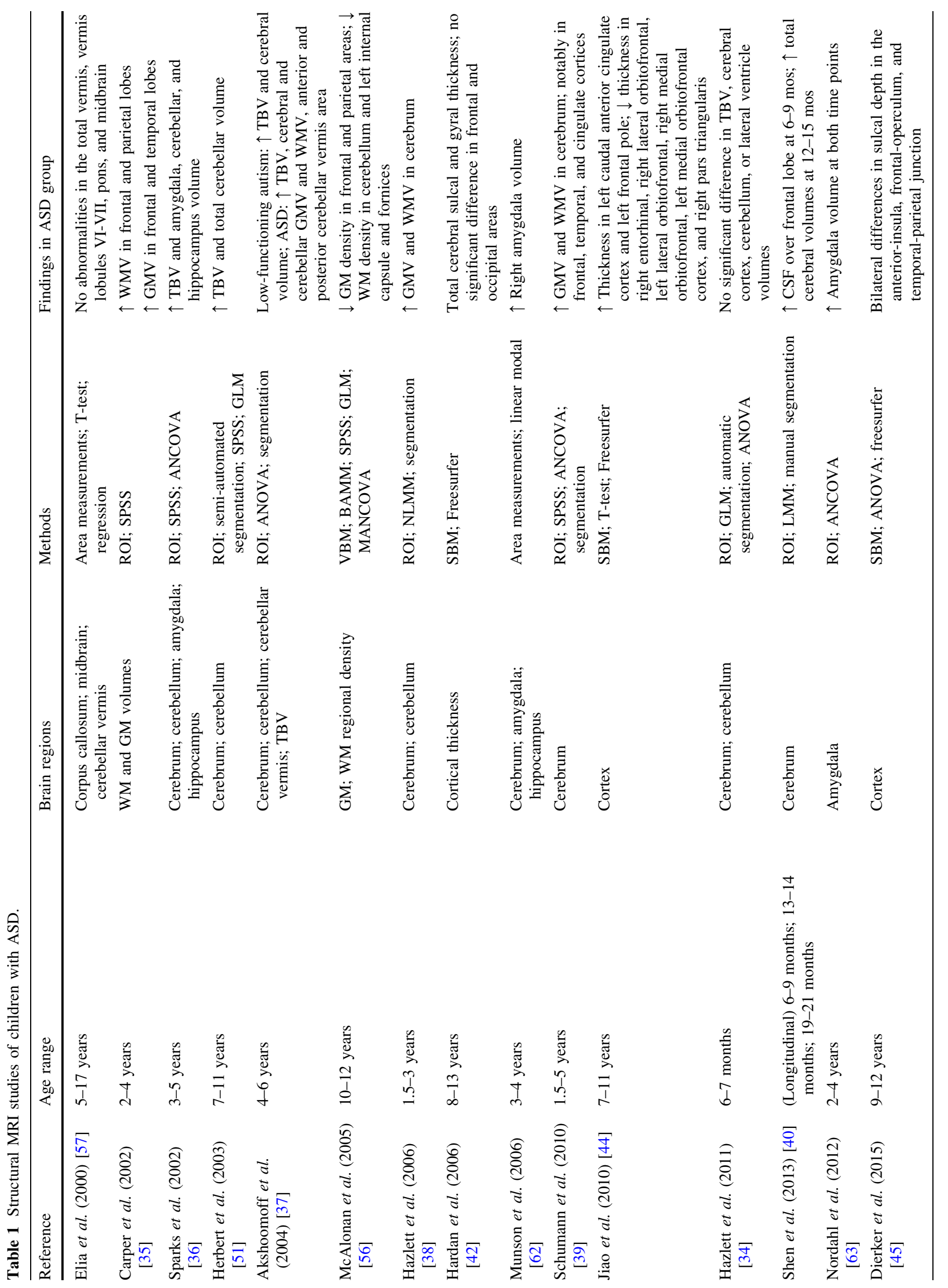




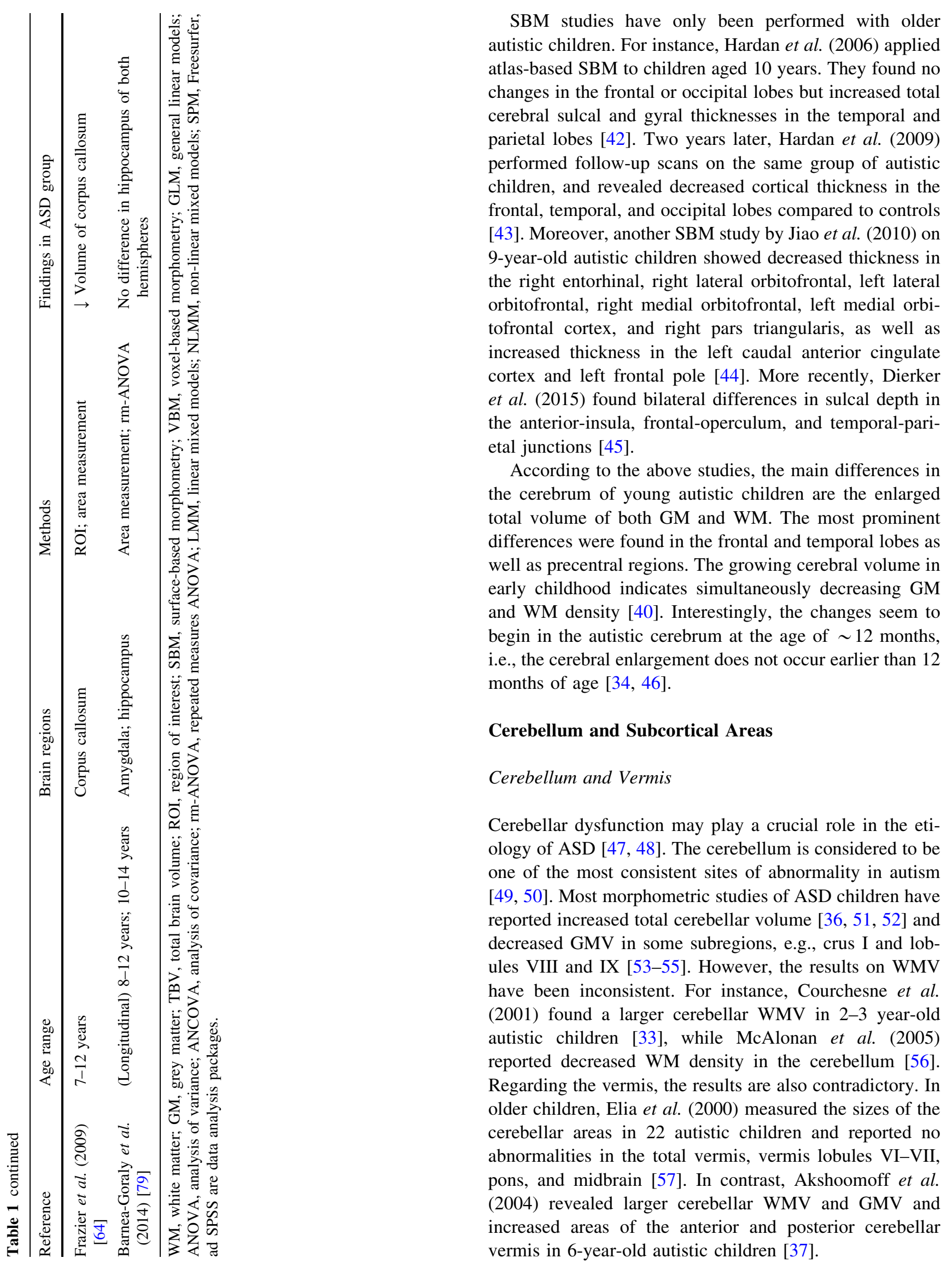




\section{Amygdala}

The amygdala has been the focus of several studies in children with ASD, given its important role in socioemotional processing [58-61]. Sparks et al. (2002) investigated 29 autistic children and typically-developing controls with an average age of 3.9 years and showed bilateral enlargement of the amygdala that was proportional to the overall increase in total cerebral volume [36]. Munson et al. (2006) argued that the enlargement was only found in the right amygdala at the age of 3-4 years [62]. Nordahl et al. (2012) scanned 85 autistic children aged 37 months on average, and re-scanned 45 members of the same group one year later. They found an increased amygdala volume in both cases, confirming that the enlargement starts at $\sim 3$ years [63].

\section{Corpus Callosum}

A decreased corpus callosum (CC) size in the autistic population has been consistently reported, including reductions localized in the mid-sagittal area, anterior CC, body, and posterior splenium [2, 22, 43, 64-69]. A reduced CC has been associated with reduced integration of information and slower processing [2, 68, 69]. However, to our knowledge, $\mathrm{CC}$ changes in the early childhood period have not yet been studied. A report by Frazier et al. (2012) investigated 19 autistic children with a mean age of 10.6 years and found consistent reductions in the total CC volume [65].

\section{Basal Ganglia}

The basal ganglia play an important role in cognition and motor control via participation in frontostriatal, thalamocortical, and limbic circuits [70-73]. In neuroimaging studies of ASD, the basal ganglia have been studied regarding their association with repetitive behaviors $[74,75]$. The most consistent finding is an increased caudate volume [76, 77]. Unfortunately, most of the studies were conducted in adults or late adolescence but not in childhood.

\section{Hippocampus}

Sparks et al. (2002) found enlarged hippocampi in autistic children at the ages of 3-4 years [36]. Similarly, in 7.5-12.5 year-olds, Schumann et al. (2004) also revealed enlarged hippocampi, especially in an HFA group [78], while in a 10 year-old group, Barnea-Goraly et al. (2014) observed an enlargement only in the right hippocampus [79]. Interestingly, in an older group, Barnea-Goraly et al. (2014) reported no difference in the hippocampus of both hemispheres. These findings indicate that the hippocampus in ASD has an unbalanced growth pattern during early brain development [79].

\section{Conclusions}

The most consistent structural MRI finding is the increased growth of total cortical volume in early ASD children. A similar trend has also been demonstrated in some subcortical brain regions (e.g., amygdala and hippocampus) and the cerebellum. Interestingly, studies comparing ASD adolescents or adults with controls did not find such differences and have even reported decreased TBV in ASD patients $[35,80]$. Thus, it seems as if brain development during early childhood in ASD is more voluminous than in a typically-developing brain, especially in the frontal and temporal lobes, followed by a possibly reduced volumetric capacity of the brain after adolescence [81, 82].

\section{Diffusion Tensor Imaging (DTI)}

Molecular studies have demonstrated dysmaturation of the WM characterized by microstructural changes or disorganization in the brains of autistic populations [83, 84]. It has been reported that synaptogenesis is altered in children with ASD, affecting myelination, and thus compromising WM integrity [85]. DTI, as a non-invasive tool, has been applied in the last decade to developing brains to study both the local connectivity and WM tracts as well as fasciculi that connect regions and lobes [2, 86-90]. Metrics such as fractional anisotropy (FA), and mean diffusivity (MD) have been used to measure the directionality and the amount of diffusion, respectively, in a particular ROI or at the level of individual voxels. The most commonly-used DTI methods are tractography, voxel-wise analysis, and tract-based spatial statistics (TBSS). Table 2 summarizes the findings of DTI studies in children.

\section{Tractography}

The majority of tractography studies have found reduced FA and increased MD, indicating more WM microstructural disorganization in the frontal and temporal lobes or dominant tracts. For example, Sundaram et al. (2008) applied deterministic tractography to analyze WM abnormalities in the frontal lobe and checked for short-range connectivity changes in ASD children. They reported higher MD in the whole frontal lobe as well as reduced FA for short-range fibers in ASD children [91]. Hong et al. (2011) also used deterministic tractography to examine connectivity in the CC in HFA children. They revealed decreased WM density in the anterior third of the $\mathrm{CC}$, as well as higher MD and a lower fiber number in the anterior 


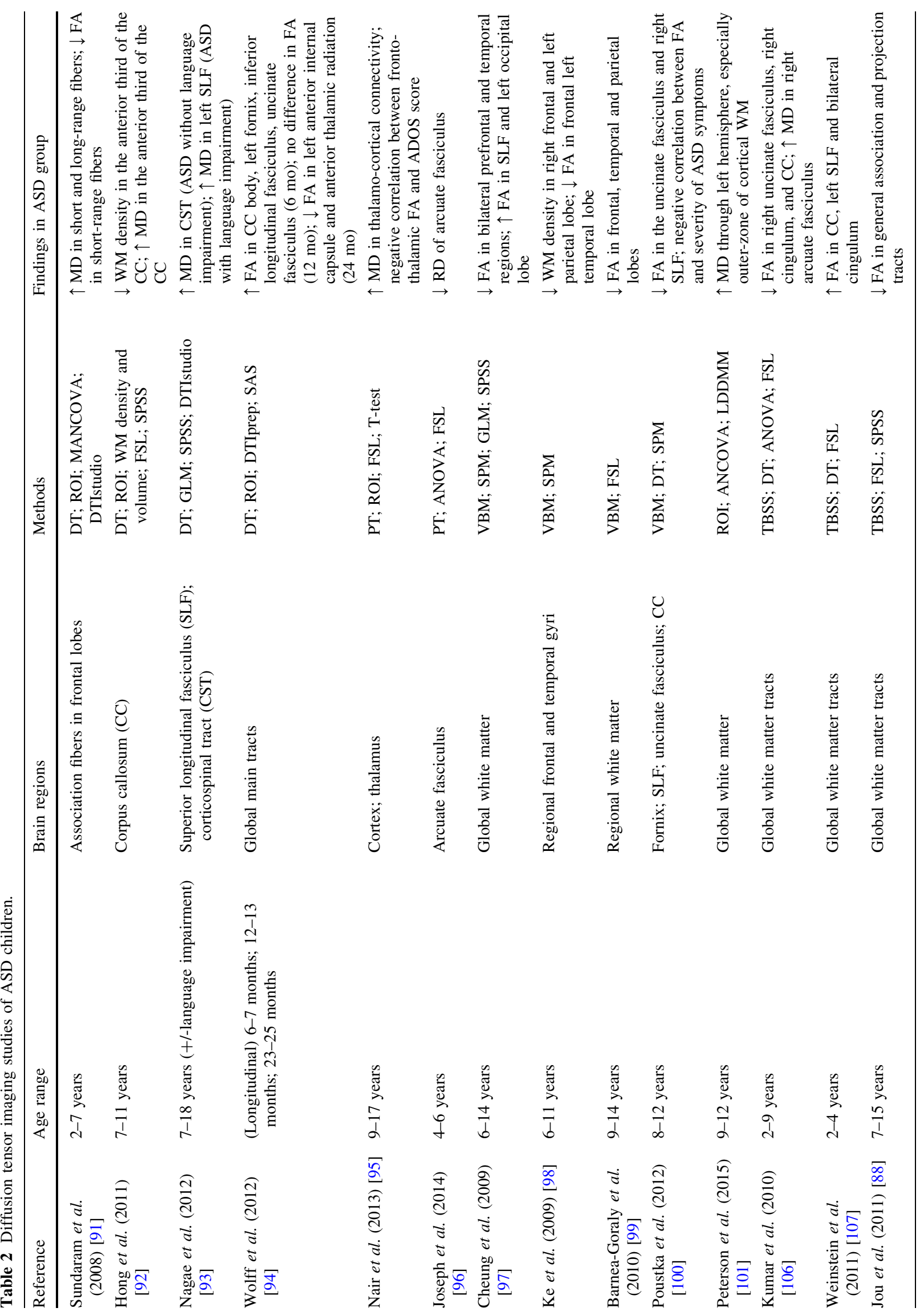


third of the transcallosal fiber tracts [92]. Using deterministic tractography, Nagae et al. (2012) revealed higher MD in the temporal portion of the left superior longitudinal fasciculus in ASD children with language impairment, as well as a significant negative correlation between MD and language score [93]. Wolff et al. (2012) investigated WM fiber tracts in a group of high-risk infants from 6 to 24 months old. Higher FA values were found in the fornix, uncinate fasciculus, and inferior longitudinal fasciculus at 6 months, whereas no such differences were observed at 12 months [94]. Nair et al. (2013) used both fMRI and probabilistic DTI tractography to assess the integrity of thalamo-cortical connectivity in children and adolescents with ASD. They reported increased MD in the thalamo-cortical connections, and decreased functional connectivity in the thalamo-cortical circuitry, as well as a negative correlation between the fronto-thalamic FA and the social and total Autism Diagnostic Observation Schedule score [95]. More recently, Joseph et al. (2014) applied both structural MRI and probabilistic DTI tractography to investigate the anatomo-behavioral relationship addressing language ability in young ASD children. In the ASD children, they found no difference in GM asymmetries but decreased leftward volume and radial diffusivity of the arcuate fasciculus [96].

\section{Voxel-Wise Analysis}

Voxel-wise analysis is used to find areas of significant difference and to overcome possible user bias. Cheung et al. (2009) reported reduced FA in bilateral prefrontal and temporal regions as well as the frontal striato-temporal and posterior brain pathways that are associated with communication and social reciprocity impairment and repetitive behavior [97]. Ke et al. (2009) investigated the WM abnormalities in a group of Chinese HFA children. The voxel-wise whole-brain analysis of FA showed decreased WM density in the right frontal lobe, left parietal lobe, and right anterior cingulate [98]. Barnea-Goraly et al. (2010) found reduced FA in age-matched unaffected siblings as compared to children with ASD, suggesting that this may be a potential marker of genetic risk [99]. Poustka et al. (2012) revealed decreased FA values in the uncinate fasciculus and right superior longitudinal fasciculus as well as a negative correlation between the FA values of the affected fiber tracts and the severity of ASD symptoms [100]. A more recent study by Peterson et al. (2015) found widespread increases in MD in many regions of the left hemisphere in children with ASD as compared to typicallydeveloping children [101], supporting the left hemispheric abnormality or atypical hemispheric dominance that has been hypothesized in ASD for the past three decades [102-104]. Peterson et al. (2015) used an atlas-based ROI analysis in HFA children and found significantly increased 
MD of the outer-zone cortical WM, suggesting hypomyelination and increased short-range cortico-cortical connections which might be due to the early WM overgrowth [101].

\section{Tract-Based Spatial Statistics (TBSS)}

A further innovative method of DTI analysis is TBSS [105]. This method provides advantages over traditional voxel-wise analysis, since it does not require smoothing and allows for a higher spatial comparability. A mean FA skeleton is built and thresholded to exclude areas of high inter-individual variability. Each individual's FA map is then projected onto the skeleton to collect standard voxelwise FA statistics across all the individuals. Kumar et al. (2010) combined deterministic tractography and TBSS to investigate the $\mathrm{CC}$ region in 5-year-old ASD children. They found lower FA, higher MD, larger numbers of streamlines and voxels, and longer streamlines as well as correlation between macrostructural changes in the uncinate fasciculus and the score on the Gilliam Autism Rating Scale [106]. Weinstein et al. (2011) reported increased FA within the genu and body of the $\mathrm{CC}$, left superior longitudinal fasciculus, and right and left cingulum in a group of very young ASD children using TBSS. The tractography revealed that the increased FA was concentrated in the mid-body of the CC and in the left cingulum [107]. Jou et al. (2011) found reduced FA in the forceps minor, inferior fronto-occipital fasciculus, and superior longitudinal fasciculus [88]. Shukla et al. (2011) demonstrated reduced FA and higher MD in the $\mathrm{CC}$, anterior and posterior limbs of the internal capsule, inferior longitudinal fasciculus, inferior fronto-occipital fasciculus, superior longitudinal fasciculus, cingulum, anterior thalamic radiation, and corticospinal tract [85]. Similarly, Walker et al. (2012) revealed decreased FA values in various brain regions and increased MD in some tracts [108].

\section{Conclusions}

Studies using voxel-wise analysis have revealed decreased FA and increased MD in the major WM tracts of ASD children. However, the voxel-wise analysis of DTI has methodological disadvantages such as the dependency on the size of the smoothing kernel and the hindrance of confident conclusions [30]. TBSS overcomes these flaws and has been used in the majority of more recent and ongoing tractography studies. Predominantly the latter have revealed reduced FA and higher diffusivity in the main tracts in ASD children, including the uncinate fasciculus, arcuate fasciculus, cingulum bundle, inferior longitudinal fasciculus, and inferior fronto-occipital fasciculus.

\section{Resting-State Functional Magnetic Resonance Imaging}

Brain connectomics is a relatively new field of research that maps the brain's large-scale functional networks "at rest". Correlated and anti-correlated fMRI signals are measured without performing specific tasks. These signals imply a functional connectivity that reflects structural connectivity $[109,110]$. They can be used to explore both the spatial and temporal deviations of the topology of atypical neurodevelopmental processes [111]. Table 3 summarizes the findings of rs-fMRI studies in children.

In an attempt to elucidate putative neurobiological underpinning mechanisms, Just et al. (2004) proposed the "hypoconnectivity theory of ASD", claiming that the deficit of integration of neuronal information in ASD might be associated with an overall under-functioning of the brain's integrative circuitry [112]. However, Courchesne and Pierce (2005) suggested that the developmental trajectory for functional brain connectivity in ASD individuals is characterized by both an early local hyperconnectivity and a longdistance hypoconnectivity of the prefrontal cortex based on the findings of an increased short-range (local) connectivity within the frontal lobe but a decreased degree of functional long-range (global) connectivity with the rest of the brain [113]. Di Martino et al. (2011) found only hyperconnectivity in the superior temporal gyrus, insula, and brainstem areas [114]. Moreover, Lynch et al. (2013) and Uddin et al. (2013) both demonstrated increased connectivity in the cingulate cortex and inferior and superior frontal gyri, as well as other specific areas $[115,116]$. However, other childhood ASD studies mostly revealed reduced long-range connectivities across different brain regions [95, 117-119]. Thus, it has been suggested that the increased local connectivity in ASD children results from overcompensation for the reduced long-range connectivity [95].

\section{${ }^{1}$ H-MRS Metabolite Spectrum}

Neurochemicals are involved in cortical activity as well as in the metabolic processes in the brain. Each metabolite has a unique chemical shift which acts as a signature that is used for the quantification of that specific metabolite. The most common method of metabolite quantification in vivo is through the proton resonance of hydrogen $\left({ }^{1} \mathrm{H}\right)$ atoms [120]. ${ }^{1} \mathrm{H}$-magnetic resonance spectroscopy $\left({ }^{1} \mathrm{H}-\mathrm{MRS}\right)$ is a non-invasive imaging technique that estimates specific chemical metabolites [121]. Previous studies mainly used ${ }^{1} \mathrm{H}$-MRS to quantify creatine and phosphocreatine $(\mathrm{Cr}+\mathrm{PCr})$, a measure of cellular energy metabolism [122]; N-acetylaspartate (NAA), a marker of neuronal density and activity [123]; choline- 
Table 3 Resting-state functional MRI studies in ASD children.

\begin{tabular}{|c|c|c|c|}
\hline Reference & Age range (years) & Seed brain regions & Findings in ASD group \\
\hline Di Martino et al. (2011) [114] & $7-13$ & Striatal regions (caudate, putamen) & $\begin{array}{l}\uparrow \text { Connectivity in striatal-cortical circuitry } \\
\uparrow \text { Striatal functional connectivity with the } \\
\text { pons } \\
\uparrow \text { Connectivity of brainstem area, with } \\
\text { bilateral insular regions }\end{array}$ \\
\hline \multirow[t]{3}{*}{ Lynch et al. (2013) [115] } & $7-12$ & Precuneus & $\begin{array}{l}\downarrow \text { Connectivity to cuneus, caudate, and } \\
\text { thalamic nuclei }\end{array}$ \\
\hline & & Posterior cingulate cortex & $\begin{array}{l}\uparrow \text { Connectivity to medial and anterolateral } \\
\text { temporal cortex, lingual gyrus, posterior } \\
\text { parahippocampal gyrus, temporal pole, } \\
\text { entorhinal cortex, and perirhinal cortex } \\
\text { within the anterior aspect of the medial } \\
\text { temporal lobe }\end{array}$ \\
\hline & & Retrosplenial cortex & $\begin{array}{l}\uparrow \text { Connectivity to inferior frontal and } \\
\text { middle frontal gyrus, dorsal medial } \\
\text { prefrontal cortex, posterior insular } \\
\text { cortex, lingual gyrus, posterior } \\
\text { parahippocampal gyrus, temporal pole, } \\
\text { posterior superior temporal sulcus, and } \\
\text { anterior supramarginal gyrus }\end{array}$ \\
\hline \multirow[t]{5}{*}{ Uddin et al. (2013) [116] } & $7-12$ & Anterior cingulate cortex & $\begin{array}{l}\uparrow \text { Connectivity to superior frontal gyrus, } \\
\text { thalamus, and bilateral insular cortex }\end{array}$ \\
\hline & & Precuneus & $\begin{array}{l}\uparrow \text { Connectivity to posterior cingulate } \\
\text { cortex and left angular gyrus }\end{array}$ \\
\hline & & Superior temporal gyrus & $\uparrow$ Connectivity to middle temporal gyrus \\
\hline & & Postcentral gyrus & $\begin{array}{l}\uparrow \text { Connectivity to precentral gyrus, left } \\
\text { posterior insular cortex, and thalamus }\end{array}$ \\
\hline & & Lateral occipital cortex & $\begin{array}{l}\uparrow \text { Connectivity to intracalcarine cortex, } \\
\text { and occipital pole }\end{array}$ \\
\hline Wiggins et al. (2011) 119] & $10-18$ & Right superior frontal gyrus & $\begin{array}{l}\downarrow \text { Connectivity to posterior superior } \\
\text { frontal gyrus }\end{array}$ \\
\hline Rudie et al. (2012) [118] & \multicolumn{2}{|c|}{ 10-15 (+/-MET mutatiळ1o)sterior cingulate cortex } & $\begin{array}{l}\downarrow \text { Connectivity of overall default mode } \\
\text { network } \\
\downarrow \text { Connectivity to medial prefrontal cortex } \\
\text { in MET-homozygous } \\
\downarrow \text { Connectivity to medial prefrontal cortex } \\
\text { within ASD group }\end{array}$ \\
\hline Abrams et al. (2013) [117] & $8-12$ & Posterior superior temporal sulcus & $\begin{array}{l}\downarrow \text { Connectivity of bilateral ventral } \\
\text { tegmental area, nucleus accumbens, } \\
\text { putamen of basal ganglia, ventromedial } \\
\text { prefrontal cortex, left caudate, anterior } \\
\text { insular cortex, and orbitofrontal cortex }\end{array}$ \\
\hline \multirow[t]{2}{*}{ Nair et al. (2013) [95] } & $9-17$ & Right thalamus & $\uparrow$ Connectivity to temporal areas \\
\hline & & Thalamus & $\begin{array}{l}\downarrow \text { Connectivity to prefrontal, parietal- } \\
\text { occipital, and somatosensory cortical } \\
\text { regions }\end{array}$ \\
\hline
\end{tabular}

containing compounds, a measure primarily reflecting the constituents of cell membranes [122]; and glutamine/ glutamate/gamma-aminobutyric acid (GABA) ("Glx"). Recent ${ }^{1} \mathrm{H}$-MRS studies in ASD patients showed generally decreased NAA [124, 125], $\mathrm{Cr}+\mathrm{PCr}$, choline, and Glx [125], as well as increased Glx in adults [126]. However, previous studies also exhibited some inconsistencies, such as decreased [127-131], unchanged, or increased NAA in ASD children compared with controls [127, 132-135]. In the following, we categorize the recent ${ }^{1} \mathrm{H}$-MRS studies in young individuals with ASD according to the four main detectable chemical metabolites: $\mathrm{Cr}+\mathrm{PCr}$, NAA, choline, and Glx. Table 4 summarizes the findings of MRS studies in children. 
Table 4 MRS studies in ASD children.

\begin{tabular}{|c|c|c|c|c|c|c|}
\hline Reference & $\begin{array}{l}\text { Age range } \\
\text { (years) }\end{array}$ & $\mathrm{Cr}+\mathrm{PCr}$ & NAA & Cho & Glx & Findings in ASD group \\
\hline Friedman et al. (2003) [129] & $3-4$ & $\sqrt{ }$ & $\sqrt{ }$ & $\sqrt{ }$ & & $\begin{array}{l}\downarrow \mathrm{Cr}+\mathrm{PCr} \text { in frontal, parietal, temporal, occipital and } \\
\text { thalamus } \\
\downarrow \text { NAA in bilateral frontal, parietal, and cingulate areas, } \\
\text { and in right superior temporal gyrus and left putamen } \\
\downarrow \text { Cho in cortical areas, temporal lobes, and thalamus }\end{array}$ \\
\hline DeVito et al. (2007) [128] & $6-17$ & $\sqrt{ }$ & $\sqrt{ }$ & $\sqrt{ }$ & $\sqrt{ }$ & $\begin{array}{l}\downarrow \mathrm{Cr}+\mathrm{PCr} \text { in GM of frontal, temporal, occipital cortices } \\
\text { and cerebellum } \\
\downarrow \text { Cho in cortical areas, temporal lobes, and thalamus } \\
\downarrow \text { Glx in GM of frontal, occipital, and temporal regions } \\
\text { as well as cerebellum }\end{array}$ \\
\hline Hardan et al. (2008) [130] & $8-15$ & $\sqrt{ }$ & $\sqrt{ }$ & & $\sqrt{ }$ & $\begin{array}{l}\downarrow \mathrm{Cr}+\mathrm{PCr} \text { in bilateral thalamus } \\
\downarrow \text { Cho in cortical areas, temporal lobes, and thalamus } \\
\uparrow \text { Glx of thalamus is associated with abnormal sensory } \\
\text { sensitivity and deficits in body movement modulation }\end{array}$ \\
\hline Corrigan et al. (2013) [138] & $3-4$ & $\sqrt{ }$ & $\sqrt{ }$ & $\sqrt{ }$ & $\sqrt{ }$ & $\begin{array}{l}\downarrow \mathrm{Cr}+\mathrm{PCr} \text { in GM and WM generally } \\
\downarrow \text { Cho in cortical areas, temporal lobes, and thalamus } \\
\text { generally }\end{array}$ \\
\hline Levitt et al. (2003) [131] & $5-16$ & $\sqrt{ }$ & $\sqrt{ }$ & $\sqrt{ }$ & & $\begin{array}{l}\downarrow \mathrm{Cr}+\mathrm{PCr} \text { in frontal, parietal, temporal, occipital, and } \\
\text { thalamus } \\
\downarrow \text { NAA in bilateral frontal and parietal areas, and in the } \\
\text { left caudate } \\
\downarrow \text { Cho in cortical areas, temporal lobes, and thalamus } \\
\uparrow \text { Cho in caudate, anterior cingulate cortex and } \\
\text { hippocampus-amygdala complex }\end{array}$ \\
\hline Friedman et al. (2006) [144] & $3-4$ & $\sqrt{ }$ & $\sqrt{ }$ & $\sqrt{ }$ & $\sqrt{ }$ & $\begin{array}{l}\downarrow \text { NAA in both GM and WM generally } \\
\downarrow \text { Cho in cortical areas, temporal lobes, and thalamus }\end{array}$ \\
\hline Corrigan et al. (2013) [138] & $3-4$ & $\sqrt{ }$ & $\sqrt{ }$ & $\sqrt{ }$ & $\sqrt{ }$ & $\begin{array}{l}\downarrow \text { NAA in both GM and WM in cortical regions } \\
\downarrow \text { Glx in both cortical GM and WM generally }\end{array}$ \\
\hline Fujii et al. (2010) [145] & $2-13$ & $\sqrt{ }$ & $\sqrt{ }$ & $\sqrt{ }$ & & $\begin{array}{l}\downarrow \mathrm{NAA} / \mathrm{Cr}+\mathrm{PCr} \text { in anterior cingulate cortex and a } \\
\text { deficit in executive functions }\end{array}$ \\
\hline Fayed et al. (2005) [178] & $2-10$ & & $\sqrt{ }$ & $\sqrt{ }$ & & $\begin{array}{l}\downarrow \text { Cho in both GM and WM of cortical areas, temporal } \\
\text { lobes and thalamus }\end{array}$ \\
\hline Vasconcelos et al. (2008) [148] & $6-10$ & $\sqrt{ }$ & $\sqrt{ }$ & $\sqrt{ }$ & $\sqrt{ }$ & $\begin{array}{l}\downarrow \mathrm{Cr}+\mathrm{PCr} \text { in cerebellum and striatum } \\
\downarrow \mathrm{NAA} \text { in frontal areas } \\
\uparrow \mathrm{Cho} \text { in caudate, anterior cingulate cortex, and } \\
\text { hippocampus-amygdala complex }\end{array}$ \\
\hline Gabis et al. (2008) [146] & $8-14$ & & $\sqrt{ }$ & $\sqrt{ }$ & & $\begin{array}{l}\downarrow \text { NAA in Hippocampus-amygdala complex } \\
\uparrow \text { Cho in caudate, anterior cingulate cortex, and } \\
\text { hippocampus-amygdala complex }\end{array}$ \\
\hline Doyle-Thomas et al. (2014) [151] & $7-18$ & $\sqrt{ }$ & $\sqrt{ }$ & $\sqrt{ }$ & $\sqrt{ }$ & $\begin{array}{l}\downarrow \mathrm{Glx} / \mathrm{Cr}+\mathrm{PCr} \text { in cerebellum and } \uparrow \mathrm{Glx} / \mathrm{Cr}+\mathrm{PCr} \text { in } \\
\text { putamen } \\
\downarrow \mathrm{NAA} / \mathrm{Cr}+\mathrm{PCr} \text { in thalamus and } \uparrow \mathrm{NAA} / \mathrm{Cr}+\mathrm{PCr} \text { in } \\
\text { caudate }\end{array}$ \\
\hline
\end{tabular}

Cho, Choline; $\mathrm{Cr}+\mathrm{PCr}$, creatine and phosphocreatine; Glx, glutamine,glutamate and GABA; GM, grey matter; NAA, N-acetylaspartate; WM, white matter.

\section{Creatine and Phosphocreatine}

In ${ }^{1} \mathrm{H}-\mathrm{MRS}, \mathrm{Cr}$ and $\mathrm{PCr}$ are quantified together [136]. They play a crucial role in the adenosine triphosphate (ATP) and adenosine diphosphate (ADP) energy-transfer process.
ATP results from oxidative phosphorylation in neuronal and glial mitochondria and glycolysis in the cytosol. A phosphate bond is released from ATP through the enzyme creatine kinase to store energy. The free phosphate bond then binds with $\mathrm{Cr}$ to form $\mathrm{PCr}$. When cellular 
mitochondria require energy, ADP and a third phosphate bond are resynthesized to ATP via oxidative phosphorylation $[122,136,137] . \mathrm{Cr}$ is highly-expressed in the mitochondria of neurons and is crucial for cellular energy production and in the maintenance of cortical homeostasis [122, 137].

In children with $\mathrm{ASD}$, reduced $\mathrm{Cr}+\mathrm{PCr}$ levels have been reported across the cortical regions [128-130, 138]. Turner and Gant (2014) reviewed the biochemistry of $\mathrm{Cr}$ and revealed an association between reduced $\mathrm{Cr}+\mathrm{PCr}$ and ASD-like behaviors, such as abnormal learning skills, intellectual disability, and repetitive and compulsive behaviors. This correlation could be due to delayed or impaired axon growth during brain development, in which $\mathrm{Cr}+\mathrm{PCr}$ are crucial elements [139]. However, no correlation between $\mathrm{Cr}+\mathrm{PCr}$ levels and autistic symptom severity has been found in children with ASD [140]. Moreover, cortical $\mathrm{Cr}+\mathrm{PCr}$ is commonly considered to be stable and has been extensively used as a reference for other metabolites [120, 122, 127, 136].

\section{N-Acetylaspartate (NAA)}

NAA is synthesized in the mitochondria of neurons and is catabolized in glial cells and oligodendrocytes, acting as a precursor of fatty-acids to form the myelin around axons [137]. Quantified by ${ }^{1} \mathrm{H}-\mathrm{MRS}$, the NAA level is considered to reflect neuronal density, integrity, and metabolism $[104,131,136,141]$. It is well accepted that NAA is comparable across both GM and WM, while it is more abundant in WM than in GM, due to its role in transmission of action potentials [142, 143].

Research on NAA has revealed a consistent phenomenon, i.e., it is generally reduced in children with ASD. In a group of 3-4 year-old ASD children, Friedman et al. (2003) reported NAA reduction in the frontal, parietal, and cingulate areas of both hemispheres, as well as in the right superior temporal gyrus and left putamen, compared with typically-developing children [129]. In an older group of ASD children with a mean age of 10.4 years, Levitt et al. (2003) revealed similar findings of reduced NAA in both left and right frontal and parietal areas, as well as in the left caudate. They also claimed that reduced parietal axon density, marked by reduced WM NAA, is associated with deficits in eye gaze, spatial perception, and memory [131]. Comparing children with ASD and those with pervasive developmental disorder, Friedman et al. (2006) found an extensively decreased NAA level in the ASD group across both GM and WM [144]. Similarly, Corrigan et al. (2013) found a general NAA reduction across most cortical regions in both GM and WM [138]. Interestingly, Fujii et al. (2010) reported a relationship between a reduced $\mathrm{NAA} / \mathrm{Cr}+\mathrm{PCr}$ ratio in the anterior cingulate cortex and a deficit in executive functions. Moreover, they also found a correlation between decreased $\mathrm{NAA} / \mathrm{Cr}+\mathrm{PCr}$ and social and communication disabilities [145].

\section{Choline}

Choline is synthesized in the liver and is essential for the synthesis of the neurotransmitter acetylcholine. Cholinecontaining compounds along with membrane phospholipids make up $40 \%$ of myelin. In ${ }^{1} \mathrm{H}-\mathrm{MRS}$, the choline level is highest in the WM [120]. The cortical choline levels indicate the equilibrium of neuronal cellular membrane phospholipid metabolism [120, 137, 146, 147].

In children with ASD, choline-containing compounds are generally decreased in cortical areas, the temporal lobes, and thalamus [128-131, 138], indicating a deficit in membrane phospholipid turnover. However, studies have also reported increased choline levels in ASD children in different brain regions, e.g. caudate, anterior cingulate cortex, and hippocampus-amygdala complex [131, 146, 148]. Even though the findings are contradictory, they revealed a similar phenomenon, that ASD children have neural maturation different from typicallydeveloping children.

\section{Glx (Glutamate, Glutamine, and GABA)}

Glx are the most abundant neurotransmitters $(90 \%$ in synapses), taking up to $60 \%-80 \%$ of the glucose oxidation and energy consumption in cortical neurons [149, 150]. They are most concentrated in GM and play essential roles in neural migration, differentiation, and plasticity [125, 132, 136, 140]. In ASD children, De Vito et al. (2007) reported extensive reduction of Glx in the GM of frontal, occipital, and temporal regions as well as the cerebellum [128]. Corrigan et al. (2013) reported a general decrease in Glx in both cortical GM and WM [138]. Harden et al. (2008) pointed out that abnormal sensory sensitivity and deficits in body movement modulation are associated with increased thalamic Glx [130]. In addition, Doyle-Thomas et al. (2014) demonstrated that an increased thalamic Glx level is associated with disabled social interaction [151].

\section{MRI and Genetics}

As outlined in the introduction, ASD has a strong genetic basis. Biological studies have revealed that many ASDrelated genes influence the formation of neuronal circuits [21, 152, 153]. However, little is known about how these genes affect brain structure and function. As reviewed above, altered brain structures and functions have 
continuously been reported in ASD with a satisfying amount of consistency. Since brain structure and function are heritable [21, 154-156], gene-related imaging may serve to demonstrate the possible neural mechanisms through which phenotypic heterogeneity arises from genetic heterogeneity in ASD [21].

One innovative gene-related imaging study has compared ASD children carrying positively testable ASD-related gene(s) with typically-developing controls [118]. In particular, the authors were interested in the MET (Met Receptor Tyrosine) gene. They combined fMRI, rs-fMRI, and DTI in a large sample of ASD children $(n=164)$ with MET gene classification and controls. Indeed, the presence of risk alleles in ASD children had a significantly larger impact on functional connectivity than controls. In the ASD risk-allele group, the fMRI showed reduced functional connectivity from posterior cingulate to medial prefrontal cortex. DTI exhibited decreased FA in the splenium portion of the $\mathrm{CC}$ that connects to the posterior cingulate. Moreover, group-by-genotype interactions revealed more deactivation of the posterior cingulate, medial prefrontal, and primary auditory cortices, lower functional connectivity of these regions, and lower WM integrity in tracts connecting these regions (splenium, cingulum, and superior and inferior longitudinal fasciculus). Investigating the impact of another ASD-related gene (CNTNAP2; contactin-associated protein-like 2), Scott-Van Zeeland et al. (2010) revealed that risk-allele-carrying ASD children showed a pattern of diffusely increased functional connectivity between the frontal cortex and temporal lobes, while typically-developing controls exhibited a clear connectivity between frontal cortex- and language-related cortical regions [157].

According to these limited findings, we can only speculate that ASD-related genes may contribute to atypical connectivity and development. More studies combining genetic information and multimodal neuroimaging data are needed to understand the relationship between heterogeneous neuropathological phenotypes and the clinical manifestations of ASD, as well as to improve diagnostic tools and treatment strategies [158].

\section{Support Vector Machine Technologies}

The findings of MRI studies have substantially advanced our understanding of the neural mechanisms underpinning ASDs. However, the integration of neuroimaging tools into clinical practice has so far been limited, partly because it is unclear which information revealed by these tools is relevant to diagnosis and treatment decisions. Support Vector Machine (SVM) technology is a specific type of supervised machine learning that aims to classify data points by maximizing the margin between classes in a high-dimensional space $[159,160]$. The optimal SVM algorithm is developed through a "training" phase in which training data are used to develop an algorithm able to discriminate between groups previously defined by the operator (e.g. patients versus controls). Once a socalled "decision function" or "hyperplane" is learned from the training data, it can be used to predict the class of a new test example. The interesting aspect of the SVM is that it is multivariate and takes into account inter-regional correlations. Therefore, it is extremely well-suited to take into account and test subtle differences in intra-regional correlations of brain metabolism, function, and anatomy $[161,162]$. This may be of particular relevance to ASD, in which the abnormalities are usually in the development of the whole neural system rather than isolated regions.

SVMs have been widely used to aid the diagnosis of neurological disorders, such as Alzheimer's disease [163-166] and Parkinson's disease [167, 168], as well as to identify those brain areas in stroke patients that are involved in a particular (cognitive) function [169, 170]. Among ASD patients, the SVM was first applied in adults. Singh et al. developed a diagnostic model generated by the LPboost-based algorithm to distinguish autistic children from controls, based on voxel-wise cortical thickness and $\sim 40,000$ points for each individual; they reported $89 \%$ classification accuracy based on cross-validation [171]. Ecker et al. (2010) applied SVM classifiers to investigate the predictive value of wholebrain structural volumetric changes in ASD, and obtained $81 \%$ classification accuracy based on cross-validation [172]. More recently, Ecker et al. (2013) pooled regional WM and GM volumes in ASD patients using SVMs and classified ASD patients with a high true positive rate [173]. As for ASD children, the number of reports is relatively limited. In a group of ASD children (mean age $9.2 \pm 2.1$ years), Jiao et al. (2010) used 4 different machine-learning techniques (including SVMs) to generate diagnostic models from both the VBM and SBM results. They reported a better classification performance for the thickness-based data than those based on regional volumes [44]. Lately, Jin et al. (2015) used an SVM classifier to identify high-risk ASD infants from WM tracts and whole-brain connectivity. Their proposed function achieved an accuracy of $76 \%$ and an area of 0.8 under the receiver operating characteristic curve [174].

To conclude, SVM technology is extremely promising in its contribution to an accurate and valid diagnosis of ASD. However, for ASD in children, the application of SVM is still at the beginning. More studies are needed to produce reliable diagnostic models based on imaging data. 
Table 5 Summary of main MRI findings.

\begin{tabular}{|c|c|}
\hline MRI approaches & Findings \\
\hline Structural MRI & $\begin{array}{l}\text { Cortex } \\
\text { Increased total GM and WM volumes } \\
\text { Increased GM and WM volumes in frontal and temporal areas } \\
\text { Increased cingulate cortex } \\
\text { Atypical variation of cortical thickness in frontal, temporal, and parietal lobes } \\
\text { Cerebellum and subcortical areas } \\
\text { Cerebellum } \\
\text { Increased total volume } \\
\text { Increased GM volume } \\
\text { Decreased WM density } \\
\text { Amygdala } \\
\text { Increased volumes in younger children bilaterally } \\
\text { Trajectory of development of amygdala follows overall trajectory of TBV } \\
\text { Corpus callosum } \\
\text { Decreased overall size } \\
\text { Increased regional volume } \\
\text { Basal ganglia } \\
\text { Increased caudate volume } \\
\text { Atypical shapes of the structures } \\
\text { Hippocampus } \\
\text { Increased size of hippocampi in young children } \\
\text { Enlargement located especially on the right side } \\
\text { No difference between sides in older children }\end{array}$ \\
\hline Diffusion tensor imaging & $\begin{array}{l}\text { Decreased FA in the whole brain, frontal lobe, arcuate fasciculus, across the entire } \mathrm{CC} \text {, and in anterior thalamic } \\
\text { radiation } \\
\text { Increased FA in arcuate fasciculus and in } \mathrm{CC} \text { in young children } \\
\text { Increased MD in whole brain, frontal and temporal lobes, and across the entire CC }\end{array}$ \\
\hline Resting-state fMRI & $\begin{array}{l}\text { Altered functional connectivity in the default mode network } \\
\text { Hyper-connectivity in striatal-cortical circuitry, precuneus, cingulate cortex, and temporal-frontal circuity } \\
\text { Under-connectivity in anterior-posterior connections }\end{array}$ \\
\hline $\begin{array}{l}\text { Magnetic resonance } \\
\text { spectroscopy }\end{array}$ & $\begin{array}{l}\text { Decreased NAA levels in general GM and WM, especially in frontal, temporal, cingulate, and caudate areas } \\
\text { Decreased Cr+PCr levels in general GM and WM, especially in frontal, parietal, temporal, occipital cortex, and } \\
\text { thalamus } \\
\text { Decreased choline levels in cortical areas, temporal lobes, and thalamus } \\
\text { Increased choline levels in caudate, anterior cingulate cortex, and hippocampus-amygdala complex } \\
\text { Decreased Glx in GM of frontal, occipital, temporal cortex, and cerebellar regions } \\
\text { Increased Glx in thalamus and putamen }\end{array}$ \\
\hline
\end{tabular}

\section{Summary and Future Direction}

The main findings of MRI studies in children are summarized in Table 5.

Young ASD children exhibit differences in brain morphometry, neurochemical components, and structural and functional connectivity. So far, a diverse set of potential biomarkers including genetic, biochemical, morphological, hormonal, immunological, neuropathological, neuropsychological, and behavioral biomarkers have been identified. However, for most of these markers it is not yet clear if they are contributing factors to the development of ASD or are a result of another underlying abnormality. Longitudinal studies - especially covering very young children with ASD - may help answer this question.

It should be kept in mind that MRI techniques are limited to a certain level of spatial and temporal resolution. If this level is not precise enough to visualize the synaptic or neuronal abnormalities where the core features or heterogeneity of ASD arises neuroimaging may ultimately not be the best tool for parsing these differences. However, in combination with postmortem tissue analysis or animal models, neuroimaging studies 
have the potential to provide a critical intermediate step between the genetic basis and the phenotype. Such approaches allow us to deconstruct the conceptions of ASD deeply to where they can be grounded in biology [87, 175].

While most of the studies reviewed here are still characterized by methodological variability and relatively small sample sizes, studies with pooled data samples and homogeneous analytical approaches are needed. Largescale collaboration networks of that type are ABIDE ("Autism Brain Imaging Data Exchange") [114, 176, 177] and NDAR ("National Database for Autism Research"). They combine imaging data from multiple sites and integrate both genetic and behavioral data. These projects will allow researchers to achieve sufficient power to detect true brain-gene-behavior relationships [21]. In general, multisite and multi-modal studies based on large patient groups is one of the key strategies to increase the probability of the discovery of new effective biomarkers in ASD and to comprehensively characterize the clinical, behavioral, and cognitive symptoms of this disorder.

Along with the growing numbers of gene-related MRI studies, the application of multimodal MRI scanning and collaboration networks, as well as advanced analytical methods are needed. Techniques, such as a machine learning classifier or prediction, may serve to identify patterns of biomarkers across different modalities, relevant to clinical diagnosis and genotype, severity rating, prognosis, and/or response to treatment. Last but not least, further large-sample studies on ASD children are needed to search for reliable biomarker patterns and diagnostic models based on imaging data.

Open Access This article is distributed under the terms of the Creative Commons Attribution 4.0 International License (http://crea tivecommons.org/licenses/by/4.0/), which permits unrestricted use, distribution, and reproduction in any medium, provided you give appropriate credit to the original author(s) and the source, provide a link to the Creative Commons license, and indicate if changes were made.

\section{References}

1. American Psychiatric Publishing. Autism spectrum disorder fact sheet. Bethesda, MD: NINDS, 2016.

2. Alexander AL, Lee JE, Lazar M, Boudos R, DuBray MB, Oakes $\mathrm{TR}$, et al. Diffusion tensor imaging of the corpus callosum in Autism. Neuroimage 2007, 34: 61-73.

3. Christensen DL, Baio J, Van Naarden Braun K, Bilder D, Charles J, Constantino JN, et al. Prevalence and characteristics of autism spectrum disorder among children aged 8 years-autism and developmental disabilities monitoring network, 11 sites, United States, 2012. MMWR Surveill Summ 2016, 65: 1-23.

4. Buescher AV, Cidav Z, Knapp M, Mandell DS. Costs of autism spectrum disorders in the United Kingdom and the United States. JAMA Pediatr 2014, 168: 721-728.
5. Fein D, Barton M, Eigsti IM, Kelley E, Naigles L, Schultz RT, et al. Optimal outcome in individuals with a history of autism. J Child Psychol Psychiatry 2013, 54: 195-205.

6. Goldani AA, Downs SR, Widjaja F, Lawton B, Hendren RL. Biomarkers in autism. Front Psychiatry 2014, 5: 100.

7. El-Fishawy P, State MW. The genetics of autism: key issues, recent findings, and clinical implications. Psychiatr Clin N Am 2010, 33: 83-105.

8. Griswold AJ, Ma D, Cukier HN, Nations LD, Schmidt MA, Chung RH, et al. Evaluation of copy number variations reveals novel candidate genes in autism spectrum disorder-associated pathways. Hum Mol Genet 2012, 21: 3513-3523.

9. Iossifov I, Ronemus M, Levy D, Wang Z, Hakker I, Rosenbaum $\mathrm{J}$, et al. De novo gene disruptions in children on the autistic spectrum. Neuron 2012, 74: 285-299.

10. Lee TL, Raygada MJ, Rennert OM. Integrative gene network analysis provides novel regulatory relationships, genetic contributions and susceptible targets in autism spectrum disorders. Gene 2012, 496: 88-96.

11. Ma D, Salyakina D, Jaworski JM, Konidari I, Whitehead PL, Andersen AN, et al. A genome-wide association study of autism reveals a common novel risk locus at 5p14.1. Ann Hum Genet 2009, 73: 263-273.

12. Murdoch JD, State MW. Recent developments in the genetics of autism spectrum disorders. Curr Opin Genet Dev 2013, 23: 310-315.

13. Ronald A, Butcher LM, Docherty S, Davis OS, Schalkwyk LC, Craig IW, et al. A genome-wide association study of social and non-social autistic-like traits in the general population using pooled DNA, $500 \mathrm{~K} \mathrm{SNP}$ microarrays and both community and diagnosed autism replication samples. Behav Genet 2010, 40: 31-45.

14. Sanders SJ, Murtha MT, Gupta AR, Murdoch JD, Raubeson MJ, Willsey AJ, et al. De novo mutations revealed by whole-exome sequencing are strongly associated with autism. Nature 2012, 485: 237-241.

15. State MW, Levitt $P$. The conundrums of understanding genetic risks for autism spectrum disorders. Nat Neurosci 2011, 14: 1499-1506.

16. Wang K, Zhang H, Ma D, Bucan M, Glessner JT, Abrahams BS, et al. Common genetic variants on $5 \mathrm{p} 14.1$ associate with autism spectrum disorders. Nature 2009, 459: 528-533.

17. Weiss LA, Arking DE, Gene Discovery Project of Johns Hopkins \& the Autism Consortium, Daly MJ, Chakravarti A. A genome-wide linkage and association scan reveals novel loci for autism. Nature 2009, 461: 802-808.

18. Persico AM, Napolioni V. Autism genetics. Behav Brain Res 2013, 251: 95-112.

19. Ruggeri B, Sarkans U, Schumann G, Persico AM. Biomarkers in autism spectrum disorder: the old and the new. Psychopharmacology 2014, 231: 1201-1216.

20. Zafeiriou DI, Ververi A, Dafoulis V, Kalyva E, Vargiami E. Autism spectrum disorders: the quest for genetic syndromes. Am J Med Genet B Neuropsychiatr Genet 2013, 162B: 327-366.

21. Hernandez LM, Rudie JD, Green SA, Bookheimer S, Dapretto M. Neural signatures of autism spectrum disorders: insights into brain network dynamics. Neuropsychopharmacology 2015, 40: 171-189.

22. Mahajan R, Mostofsky SH. Neuroimaging endophenotypes in autism spectrum disorder. CNS Spectr 2015, 20: 412-426.

23. Lenroot RK, Yeung PK. Heterogeneity within autism spectrum disorders: what have we learned from neuroimaging studies? Front Hum Neurosci 2013, 7: 733.

24. Ha S, Sohn IJ, Kim N, Sim HJ, Cheon KA. Characteristics of brains in autism spectrum disorder: structure, function and 
connectivity across the lifespan. Exp Neurobiol 2015, 24: 273-284

25. Yerys BE, Herrington JD. Multimodal imaging in autism: an early review of comprehensive neural circuit characterization. Curr Psychiatry Rep 2014, 16: 496.

26. Sacrey LA, Bennett JA, Zwaigenbaum L. Early infant development and intervention for autism spectrum disorder. J Child Neurol 2015, 30: 1921-1929.

27. Zwaigenbaum L, Bauman ML, Stone WL, Yirmiya N, Estes A, Hansen RL, et al. Early identification of autism spectrum disorder: recommendations for practice and research. Pediatrics 2015, 136 Suppl. 1: S10-40.

28. Hernandez-Garcia L, Buschkuehl M. Advances in longitudinal MRI diagnostic tests. Expert Opin Med Diagn 2012, 6: 309-321.

29. Chen R, Jiao Y, Herskovits EH. Structural MRI in autism spectrum disorder. Pediatr Res 2011, 69: 63R-68R.

30. Ismail MM, Keynton RS, Mostapha MM, ElTanboly AH, Casanova MF, Gimel'farb GL, et al. Studying autism spectrum disorder with structural and diffusion magnetic resonance imaging: a survey. Front Hum Neurosci 2016, 10: 211.

31. Goldman-Rakic PS. Development of cortical circuitry and cognitive function. Child Dev 1987, 58: 601-622.

32. Panizzon MS, Fennema-Notestine C, Eyler LT, Jernigan TL, Prom-Wormley E, Neale M, et al. Distinct genetic influences on cortical surface area and cortical thickness. Cereb Cortex 2009, 19: $2728-2735$.

33. Courchesne E, Karns CM, Davis HR, Ziccardi R, Carper RA, Tigue ZD, et al. Unusual brain growth patterns in early life in patients with autistic disorder: an MRI study. Neurology 2001, 57: 245-254.

34. Hazlett HC, Poe MD, Gerig G, Styner M, Chappell C, Smith $\mathrm{RG}$, et al. Early brain overgrowth in autism associated with an increase in cortical surface area before age 2 years. Arch Gen Psychiatry 2011, 68: 467-476.

35. Carper RA, Moses P, Tigue ZD, Courchesne E. Cerebral lobes in autism: early hyperplasia and abnormal age effects. Neuroimage 2002, 16: 1038-1051.

36. Sparks BF, Friedman SD, Shaw DW, Aylward EH, Echelard D, Artru AA, et al. Brain structural abnormalities in young children with autism spectrum disorder. Neurology 2002, 59: 184-192.

37. Akshoomoff N, Lord C, Lincoln AJ, Courchesne RY, Carper RA, Townsend J, et al. Outcome classification of preschool children with autism spectrum disorders using MRI brain measures. J Am Acad Child Adolesc Psychiatry 2004, 43: 349-357.

38. Hazlett HC, Poe MD, Gerig G, Smith RG, Piven J. Cortical gray and white brain tissue volume in adolescents and adults with autism. Biol Psychiatry 2006, 59: 1-6.

39. Schumann CM, Bloss CS, Barnes CC, Wideman GM, Carper $\mathrm{RA}$, Akshoomoff $\mathrm{N}$, et al. Longitudinal magnetic resonance imaging study of cortical development through early childhood in autism. J Neurosci 2010, 30: 4419-4427.

40. Shen MD, Nordahl CW, Young GS, Wootton-Gorges SL, Lee A, Liston SE, et al. Early brain enlargement and elevated extraaxial fluid in infants who develop autism spectrum disorder. Brain 2013, 136: 2825-2835.

41. Gori I, Giuliano A, Muratori F, Saviozzi I, Oliva P, Tancredi R, et al. Gray matter alterations in young children with autism spectrum disorders: comparing morphometry at the voxel and regional level. J Neuroimaging 2015, 25: 866-874.

42. Hardan AY, Muddasani S, Vemulapalli M, Keshavan MS, Minshew NJ. An MRI study of increased cortical thickness in autism. Am J Psychiatry 2006, 163: 1290-1292.

43. Hardan AY, Libove RA, Keshavan MS, Melhem NM, Minshew NJ. A preliminary longitudinal magnetic resonance imaging study of brain volume and cortical thickness in autism. Biol Psychiatry 2009, 66: 320-326.
44. Jiao Y, Chen R, Ke X, Chu K, Lu Z, Herskovits EH. Predictive models of autism spectrum disorder based on brain regional cortical thickness. Neuroimage 2010, 50: 589-599.

45. Dierker DL, Feczko E, Pruett JR, Jr., Petersen SE, Schlaggar $\mathrm{BL}$, Constantino JN, et al. Analysis of cortical shape in children with simplex autism. Cereb Cortex 2015, 25: 1042-1051.

46. Chenn A, Walsh CA. Regulation of cerebral cortical size by control of cell cycle exit in neural precursors. Science 2002, 297: 365-369.

47. Becker EB, Stoodley CJ. Autism spectrum disorder and the cerebellum. Int Rev Neurobiol 2013, 113: 1-34.

48. Wang SS, Kloth AD, Badura A. The cerebellum, sensitive periods, and autism. Neuron 2014, 83: 518-532.

49. Allen G. The cerebellum in autism. Clin.Neuropsychiatry 2005, 2: $321-337$.

50. Fatemi SH, Aldinger KA, Ashwood P, Bauman ML, Blaha CD, Blatt GJ, et al. Consensus paper: pathological role of the cerebellum in autism. Cerebellum 2012, 11: 777-807.

51. Herbert MR, Ziegler DA, Deutsch CK, O'Brien LM, Lange N, Bakardjiev A, et al. Dissociations of cerebral cortex, subcortical and cerebral white matter volumes in autistic boys. Brain 2003, 126: $1182-1192$.

52. Stanfield AC, McIntosh AM, Spencer MD, Philip R, Gaur S, Lawrie SM. Towards a neuroanatomy of autism: a systematic review and meta-analysis of structural magnetic resonance imaging studies. Eur Psychiatry 2008, 23: 289-299.

53. Duerden EG, Mak-Fan KM, Taylor MJ, Roberts SW. Regional differences in grey and white matter in children and adults with autism spectrum disorders: an activation likelihood estimate (ALE) meta-analysis. Autism Res 2012, 5: 49-66.

54. Stoodley CJ. Distinct regions of the cerebellum show gray matter decreases in autism, ADHD, and developmental dyslexia. Front Syst Neurosci 2014, 8: 92.

55. Yu KK, Cheung C, Chua SE, McAlonan GM. Can Asperger syndrome be distinguished from autism? An anatomic likelihood meta-analysis of MRI studies. J Psychiatry Neurosci 2011, 36: 412-421.

56. McAlonan GM, Cheung V, Cheung C, Suckling J, Lam GY, Tai $\mathrm{KS}$, et al. Mapping the brain in autism. A voxel-based MRI study of volumetric differences and intercorrelations in autism. Brain 2005, 128: 268-276.

57. Elia M, Ferri R, Musumeci SA, Panerai S, Bottitta M, Scuderi C. Clinical correlates of brain morphometric features of subjects with low-functioning autistic disorder. J Child Neurol 2000, 15: 504-508.

58. Baron-Cohen S, Ring HA, Bullmore ET, Wheelwright S, Ashwin C, Williams SC. The amygdala theory of autism. Neurosci Biobehav Rev 2000, 24: 355-364.

59. Howard MA, Cowell PE, Boucher J, Broks P, Mayes A, Farrant $\mathrm{A}$, et al. Convergent neuroanatomical and behavioural evidence of an amygdala hypothesis of autism. Neuroreport 2000, 11: 2931-2935.

60. Schultz RT. Developmental deficits in social perception in autism: the role of the amygdala and fusiform face area. Int $\mathrm{J}$ Dev Neurosci 2005, 23: 125-141.

61. Sweeten TL, Posey DJ, Shekhar A, McDougle CJ. The amygdala and related structures in the pathophysiology of autism. Pharmacol Biochem Behav 2002, 71: 449-455.

62. Munson J, Dawson G, Abbott R, Faja S, Webb SJ, Friedman SD, et al. Amygdalar volume and behavioral development in autism. Arch Gen Psychiatry 2006, 63: 686-693.

63. Nordahl CW, Scholz R, Yang X, Buonocore MH, Simon T, Rogers $\mathrm{S}$, et al. Increased rate of amygdala growth in children aged 2-4 years with autism spectrum disorders: a longitudinal study. Arch Gen Psychiatry 2012, 69: 53-61. 
64. Frazier TW, Hardan AY. A meta-analysis of the corpus callosum in autism. Biol Psychiatry 2009, 66: 935-941.

65. Frazier TW, Keshavan MS, Minshew NJ, Hardan AY. A twoyear longitudinal MRI study of the corpus callosum in autism. J Autism Dev Disord 2012, 42: 2312-2322.

66. Freitag CM, Luders E, Hulst HE, Narr KL, Thompson PM, Toga $\mathrm{AW}$, et al. Total brain volume and corpus callosum size in medication-naive adolescents and young adults with autism spectrum disorder. Biol Psychiatry 2009, 66: 316-319.

67. Hardan AY, Minshew NJ, Keshavan MS. Corpus callosum size in autism. Neurology 2000, 55: 1033-1036.

68. Just MA, Cherkassky VL, Keller TA, Kana RK, Minshew NJ. Functional and anatomical cortical underconnectivity in autism: evidence from an FMRI study of an executive function task and corpus callosum morphometry. Cereb Cortex 2007, 17: 951-961.

69. Mason RA, Williams DL, Kana RK, Minshew N, Just MA. Theory of Mind disruption and recruitment of the right hemisphere during narrative comprehension in autism. Neuropsychologia 2008, 46: 269-280.

70. Bostan AC, Dum RP, Strick PL. Cerebellar networks with the cerebral cortex and basal ganglia. Trends Cogn Sci 2013, 17: 241-254.

71. Middleton FA, Strick PL. Basal ganglia and cerebellar loops: motor and cognitive circuits. Brain Res Brain Res Rev 2000, 31 : 236-250.

72. Middleton FA, Strick PL. Basal ganglia output and cognition: evidence from anatomical, behavioral, and clinical studies. Brain Cogn 2000, 42: 183-200.

73. Utter AA, Basso MA. The basal ganglia: an overview of circuits and function. Neurosci Biobehav Rev 2008, 32: 333-342.

74. Estes A, Shaw DW, Sparks BF, Friedman S, Giedd JN, Dawson $\mathrm{G}$, et al. Basal ganglia morphometry and repetitive behavior in young children with autism spectrum disorder. Autism Res 2011, 4: 212-220.

75. Hollander E, Anagnostou E, Chaplin W, Esposito K, Haznedar MM, Licalzi E, et al. Striatal volume on magnetic resonance imaging and repetitive behaviors in autism. Biol Psychiatry 2005, 58: 226-232.

76. Sears LL, Vest C, Mohamed S, Bailey J, Ranson BJ, Piven J. An MRI study of the basal ganglia in autism. Prog Neuropsychopharmacol Biol Psychiatry 1999, 23: 613-624.

77. Williams CA, Dagli A, Battaglia A. Genetic disorders associated with macrocephaly. Am J Med Genet A 2008, 146A: 2023-2037.

78. Schumann CM, Hamstra J, Goodlin-Jones BL, Lotspeich LJ, Kwon $\mathrm{H}$, Buonocore $\mathrm{MH}$, et al. The amygdala is enlarged in children but not adolescents with autism; the hippocampus is enlarged at all ages. J Neurosci 2004, 24: 6392-6401.

79. Barnea-Goraly N, Frazier TW, Piacenza L, Minshew NJ, Keshavan MS, Reiss AL, et al. A preliminary longitudinal volumetric MRI study of amygdala and hippocampal volumes in autism. Prog Neuropsychopharmacol Biol Psychiatry 2014, 48: 124-128.

80. Nordahl CW, Lange N, Li DD, Barnett LA, Lee A, Buonocore $\mathrm{MH}$, et al. Brain enlargement is associated with regression in preschool-age boys with autism spectrum disorders. Proc Natl Acad Sci USA 2011, 108: 20195-20200.

81. Courchesne E, Campbell K, Solso S. Brain growth across the life span in autism: age-specific changes in anatomical pathology. Brain Res 2011, 1380: 138-145.

82. Lange N, Travers BG, Bigler ED, Prigge MB, Froehlich AL, Nielsen JA, et al. Longitudinal volumetric brain changes in autism spectrum disorder ages 6-35 years. Autism Res 2015, 8: $82-93$.
83. Casanova MF, Buxhoeveden DP, Brown C. Clinical and macroscopic correlates of minicolumnar pathology in autism. J Child Neurol 2002, 17: 692-695.

84. Casanova MF, van Kooten IA, Switala AE, van Engeland H, Heinsen H, Steinbusch HW, et al. Minicolumnar abnormalities in autism. Acta Neuropathol 2006, 112: 287-303.

85. Shukla DK, Keehn B, Muller RA. Tract-specific analyses of diffusion tensor imaging show widespread white matter compromise in autism spectrum disorder. J Child Psychol Psychiatry 2011, 52: 286-295.

86. Catani M. Diffusion tensor magnetic resonance imaging tractography in cognitive disorders. Curr Opin Neurol 2006, 19: 599-606.

87. Chanraud S, Zahr N, Sullivan EV, Pfefferbaum A. MR diffusion tensor imaging: a window into white matter integrity of the working brain. Neuropsychol Rev 2010, 20: 209-225.

88. Jou RJ, Jackowski AP, Papademetris X, Rajeevan N, Staib LH, Volkmar FR. Diffusion tensor imaging in autism spectrum disorders: preliminary evidence of abnormal neural connectivity. Aust NZ J Psychiatry 2011, 45: 153-162.

89. Mukherjee P, McKinstry RC. Diffusion tensor imaging and tractography of human brain development. Neuroimaging Clin N Am 2006, 16: 19-43, vii.

90. White T, Nelson M, Lim KO. Diffusion tensor imaging in psychiatric disorders. Top Magn Reson Imaging 2008, 19: 97-109.

91. Sundaram SK, Kumar A, Makki MI, Behen ME, Chugani HT, Chugani DC. Diffusion tensor imaging of frontal lobe in autism spectrum disorder. Cereb Cortex 2008, 18: 2659-2665.

92. Hong S, Ke X, Tang T, Hang Y, Chu K, Huang H, et al. Detecting abnormalities of corpus callosum connectivity in autism using magnetic resonance imaging and diffusion tensor tractography. Psychiatry Res 2011, 194: 333-339.

93. Nagae LM, Zarnow DM, Blaskey L, Dell J, Khan SY, Qasmieh $\mathrm{S}$, et al. Elevated mean diffusivity in the left hemisphere superior longitudinal fasciculus in autism spectrum disorders increases with more profound language impairment. AJNR Am J Neuroradiol 2012, 33: 1720-1725.

94. Wolff JJ, Gu H, Gerig G, Elison JT, Styner M, Gouttard S, et al. Differences in white matter fiber tract development present from 6 to 24 months in infants with autism. Am J Psychiatry 2012, 169: 589-600.

95. Nair A, Treiber JM, Shukla DK, Shih P, Muller RA. Impaired thalamocortical connectivity in autism spectrum disorder: a study of functional and anatomical connectivity. Brain 2013, 136: 1942-1955.

96. Joseph RM, Fricker Z, Fenoglio A, Lindgren KA, Knaus TA, Tager-Flusberg H. Structural asymmetries of language-related gray and white matter and their relationship to language function in young children with ASD. Brain Imaging Behav 2014, 8: 60-72.

97. Cheung C, Chua SE, Cheung V, Khong PL, Tai KS, Wong TK, et al. White matter fractional anisotrophy differences and correlates of diagnostic symptoms in autism. J Child Psychol Psychiatry 2009, 50: 1102-1112.

98. Ke X, Tang T, Hong S, Hang Y, Zou B, Li H, et al. White matter impairments in autism, evidence from voxel-based morphometry and diffusion tensor imaging. Brain Res 2009, 1265: 171-177.

99. Barnea-Goraly N, Lotspeich LJ, Reiss AL. Similar white matter aberrations in children with autism and their unaffected siblings: a diffusion tensor imaging study using tract-based spatial statistics. Arch Gen Psychiatry 2010, 67: 1052-1060.

100. Poustka L, Jennen-Steinmetz C, Henze R, Vomstein K, Haffner $\mathrm{J}$, Sieltjes B. Fronto-temporal disconnectivity and symptom 
severity in children with autism spectrum disorder. World J Biol Psychiatry 2012, 13: 269-280.

101. Peterson D, Mahajan R, Crocetti D, Mejia A, Mostofsky S. Lefthemispheric microstructural abnormalities in children with highfunctioning autism spectrum disorder. Autism Res 2015, 8: 61-72.

102. Dawson G, Meltzoff AN, Osterling J, Rinaldi J. Neuropsychological correlates of early symptoms of autism. Child Dev 1998, 69: 1276-1285.

103. Escalante-Mead PR, Minshew NJ, Sweeney JA. Abnormal brain lateralization in high-functioning autism. J Autism Dev Disord 2003, 33: 539-543.

104. Kleinhans NM, Muller RA, Cohen DN, Courchesne E. Atypical functional lateralization of language in autism spectrum disorders. Brain Res 2008, 1221: 115-125.

105. Smith SM, Jenkinson M, Johansen-Berg H, Rueckert D, Nichols TE, Mackay CE, et al. Tract-based spatial statistics: voxelwise analysis of multi-subject diffusion data. Neuroimage 2006, 31: $1487-1505$.

106. Kumar A, Sundaram SK, Sivaswamy L, Behen ME, Makki MI, Ager $\mathrm{J}$, et al. Alterations in frontal lobe tracts and corpus callosum in young children with autism spectrum disorder. Cereb Cortex 2010, 20: 2103-2113.

107. Weinstein M, Ben-Sira L, Levy Y, Zachor DA, Ben Itzhak E, Artzi M, et al. Abnormal white matter integrity in young children with autism. Hum Brain Mapp 2011, 32: 534-543.

108. Walker L, Gozzi M, Lenroot R, Thurm A, Behseta B, Swedo S, et al. Diffusion tensor imaging in young children with autism: biological effects and potential confounds. Biol Psychiatry 2012, 72: 1043-1051.

109. Mevel K, Fransson P. The functional brain connectome of the child and autism spectrum disorders. Acta Paediatr 2016, 105: 1024-1035.

110. Rane P, Cochran D, Hodge SM, Haselgrove C, Kennedy DN, Frazier JA. Connectivity in autism: a review of MRI connectivity studies. Harv Rev Psychiatry 2015, 23: 223-244.

111. Fox PT, Friston KJ. Distributed processing; distributed functions? Neuroimage 2012, 61: 407-426.

112. Just MA, Cherkassky VL, Keller TA, Minshew NJ. Cortical activation and synchronization during sentence comprehension in high-functioning autism: evidence of underconnectivity. Brain 2004, 127: 1811-1821.

113. Courchesne E, Pierce K. Brain overgrowth in autism during a critical time in development: implications for frontal pyramidal neuron and interneuron development and connectivity. Int J Dev Neurosci 2005, 23: 153-170.

114. Di Martino A, Kelly C, Grzadzinski R, Zuo XN, Mennes M, Mairena MA, et al. Aberrant striatal functional connectivity in children with autism. Biol Psychiatry 2011, 69: 847-856.

115. Lynch CJ, Uddin LQ, Supekar K, Khouzam A, Phillips J, Menon V. Default mode network in childhood autism: posteromedial cortex heterogeneity and relationship with social deficits. Biol Psychiatry 2013, 74: 212-219.

116. Uddin LQ, Supekar K, Lynch CJ, Khouzam A, Phillips J, Feinstein C, et al. Salience network-based classification and prediction of symptom severity in children with autism. JAMA Psychiatry 2013, 70: 869-879.

117. Abrams DA, Lynch CJ, Cheng KM, Phillips J, Supekar K, Ryali $\mathrm{S}$, et al. Underconnectivity between voice-selective cortex and reward circuitry in children with autism. Proc Natl Acad Sci USA 2013, 110: 12060-12065.

118. Rudie JD, Hernandez LM, Brown JA, Beck-Pancer D, Colich $\mathrm{NL}$, Gorrindo $\mathrm{P}$, et al. Autism-associated promoter variant in MET impacts functional and structural brain networks. Neuron 2012, 75: 904-915.
119. Wiggins JL, Peltier SJ, Ashinoff S, Weng SJ, Carrasco M, Welsh RC, et al. Using a self-organizing map algorithm to detect age-related changes in functional connectivity during rest in autism spectrum disorders. Brain Res 2011, 1380: 187-197.

120. Bertholdo D, Watcharakorn A, Castillo M. Brain proton magnetic resonance spectroscopy: introduction and overview. Neuroimaging Clin N Am 2013, 23: 359-380.

121. Kato T, Inubushi T, Kato N. Magnetic resonance spectroscopy in affective disorders. J Neuropsychiatry Clin Neurosci 1998, 10: 133-147.

122. Ross B, Bluml S. Magnetic resonance spectroscopy of the human brain. Anat Rec 2001, 265: 54-84.

123. Clarke CE, Lowry M, Horsman A. Unchanged basal ganglia $\mathrm{N}$-acetylaspartate and glutamate in idiopathic Parkinson's disease measured by proton magnetic resonance spectroscopy. Mov Disord 1997, 12: 297-301.

124. Aoki Y, Kasai K, Yamasue H. Age-related change in brain metabolite abnormalities in autism: a meta-analysis of proton magnetic resonance spectroscopy studies. Transl Psychiatry 2012, 2: e69.

125. Baruth JM, Wall CA, Patterson MC, Port JD. Proton magnetic resonance spectroscopy as a probe into the pathophysiology of autism spectrum disorders (ASD): a review. Autism Res 2013, 6: 119-133.

126. Naaijen J, Lythgoe DJ, Amiri H, Buitelaar JK, Glennon JC. Fronto-striatal glutamatergic compounds in compulsive and impulsive syndromes: a review of magnetic resonance spectroscopy studies. Neurosci Biobehav Rev 2015, 52: 74-88.

127. Brown MS, Singel D, Hepburn S, Rojas DC. Increased glutamate concentration in the auditory cortex of persons with autism and first-degree relatives: a ${ }^{1} \mathrm{H}-\mathrm{MRS}$ study. Autism Res 2013, 6: $1-10$.

128. DeVito TJ, Drost DJ, Neufeld RW, Rajakumar N, Pavlosky W, Williamson $\mathrm{P}$, et al. Evidence for cortical dysfunction in autism: a proton magnetic resonance spectroscopic imaging study. Biol Psychiatry 2007, 61: 465-473.

129. Friedman SD, Shaw DW, Artru AA, Richards TL, Gardner J, Dawson G, et al. Regional brain chemical alterations in young children with autism spectrum disorder. Neurology 2003, 60: 100-107.

130. Hardan AY, Minshew NJ, Melhem NM, Srihari S, Jo B, Bansal $\mathrm{R}$, et al. An MRI and proton spectroscopy study of the thalamus in children with autism. Psychiatry Res 2008, 163: 97-105.

131. Levitt JG, O'Neill J, Blanton RE, Smalley S, Fadale D, McCracken JT, et al. Proton magnetic resonance spectroscopic imaging of the brain in childhood autism. Biol Psychiatry 2003, 54: $1355-1366$.

132. Bejjani A, O’Neill J, Kim JA, Frew AJ, Yee VW, Ly R, et al. Elevated glutamatergic compounds in pregenual anterior cingulate in pediatric autism spectrum disorder demonstrated by $1 \mathrm{H}$ MRS and 1H MRSI. PLoS One 2012, 7: e38786.

133. Murphy DG, Critchley HD, Schmitz N, McAlonan G, Van Amelsvoort T, Robertson D, et al. Asperger syndrome: a proton magnetic resonance spectroscopy study of brain. Arch Gen Psychiatry 2002, 59: 885-891.

134. O’Brien FM, Page L, O'Gorman RL, Bolton P, Sharma A, Baird $\mathrm{G}$, et al. Maturation of limbic regions in Asperger syndrome: a preliminary study using proton magnetic resonance spectroscopy and structural magnetic resonance imaging. Psychiatry Res 2010, 184: 77-85.

135. Oner O, Devrimci-Ozguven H, Oktem F, Yagmurlu B, Baskak B, Munir KM. Proton MR spectroscopy: higher right anterior cingulate $\mathrm{N}$-acetylaspartate/choline ratio in Asperger syndrome compared with healthy controls. AJNR Am J Neuroradiol 2007, 28: 1494-1498. 
136. Kousi E, Tsougos I, Eftychia K. Proton magnetic resonance spectroscopy of the central nervous system. In: Fountas K (Ed.). Novel Frontiers of Advanced Neuroimaging. InTech, 2013, pp 19-50.

137. Rae CD. A guide to the metabolic pathways and function of metabolites observed in human brain $1 \mathrm{H}$ magnetic resonance spectra. Neurochem Res 2014, 39: 1-36.

138. Corrigan NM, Shaw DW, Estes AM, Richards TL, Munson J, Friedman SD, et al. Atypical developmental patterns of brain chemistry in children with autism spectrum disorder. JAMA Psychiatry 2013, 70: 964-974.

139. Turner CE, Gant N. Chapter 2.2-the biochemistry of creatine. Mag Reson Spectrosc 2014: 91-103.

140. Page LA, Daly E, Schmitz N, Simmons A, Toal F, Deeley Q, et al. In vivo $1 \mathrm{H}$-magnetic resonance spectroscopy study of amygdala-hippocampal and parietal regions in autism. Am $\mathbf{J}$ Psychiatry 2006, 163: 2189-2192.

141. Chugani DC, Sundram BS, Behen M, Lee ML, Moore GJ. Evidence of altered energy metabolism in autistic children. Prog Neuropsychopharmacol Biol Psychiatry 1999, 23: 635-641.

142. Ford TC, Crewther DP. A comprehensive review of the ${ }^{1} \mathrm{H}-\mathrm{MRS}$ metabolite spectrum in autism spectrum disorder. Front Mol Neurosci 2016, 9: 14.

143. Pouwels PJ, Frahm J. Regional metabolite concentrations in human brain as determined by quantitative localized proton MRS. Magn Reson Med 1998, 39: 53-60.

144. Friedman SD, Shaw DW, Artru AA, Dawson G, Petropoulos H, Dager SR. Gray and white matter brain chemistry in young children with autism. Arch Gen Psychiatry 2006, 63: 786-794.

145. Fujii E, Mori K, Miyazaki M, Hashimoto T, Harada M, Kagami S. Function of the frontal lobe in autistic individuals: a proton magnetic resonance spectroscopic study. J Med Invest 2010, 57: 35-44.

146. Gabis L, Wei H, Azizian A, DeVincent C, Tudorica A, KesnerBaruch $\mathrm{Y}$, et al. 1H-magnetic resonance spectroscopy markers of cognitive and language ability in clinical subtypes of autism spectrum disorders. J Child Neurol 2008, 23: 766-774.

147. Suzuki K, Nishimura K, Sugihara G, Nakamura K, Tsuchiya KJ, Matsumoto K, et al. Metabolite alterations in the hippocampus of high-functioning adult subjects with autism. Int J Neuropsychopharmacol 2010, 13: 529-534.

148. Vasconcelos MM, Brito AR, Domingues RC, da Cruz LC, Jr., Gasparetto EL, Werner J, Jr., et al. Proton magnetic resonance spectroscopy in school-aged autistic children. J Neuroimaging 2008, 18: 288-295.

149. Brady S Seigel G, Albers RW, et al. Basic Neurochemistry: Principles of Molecular, Cellular and Medical Neurobiology. Cambridge: Elsevier Academic Press, 2011.

150. Rothman DL, Behar KL, Hyder F, Shulman RG. In vivo NMR studies of the glutamate neurotransmitter flux and neuroenergetics: implications for brain function. Annu Rev Physiol 2003, 65: 401-427.

151. Doyle-Thomas KA, Card D, Soorya LV, Wang AT, Fan J, Anagnostou E. Metabolic mapping of deep brain structures and associations with symptomatology in autism spectrum disorders. Res Autism Spectr Disord 2014, 8: 44-51.

152. Parikshak NN, Luo R, Zhang A, Won H, Lowe JK, Chandran V, et al. Integrative functional genomic analyses implicate specific molecular pathways and circuits in autism. Cell 2013, 155: $1008-1021$.

153. Won H, Mah W, Kim E. Autism spectrum disorder causes, mechanisms, and treatments: focus on neuronal synapses. Front Mol Neurosci 2013, 6: 19 .

154. Chiang MC, McMahon KL, de Zubicaray GI, Martin NG, Hickie I, Toga AW, et al. Genetics of white matter development: a DTI study of 705 twins and their siblings aged 12-29. Neuroimage 2011, 54: 2308-2317.
155. Fornito A, Zalesky A, Bassett DS, Meunier D, Ellison-Wright I, Yucel M, et al. Genetic influences on cost-efficient organization of human cortical functional networks. J Neurosci 2011, 31: 3261-3270.

156. Glahn DC, Winkler AM, Kochunov P, Almasy L, Duggirala R, Carless MA, et al. Genetic control over the resting brain. Proc Natl Acad Sci USA 2010, 107: 1223-1228.

157. Scott-Van Zeeland AA, Abrahams BS, Alvarez-Retuerto AI, Sonnenblick LI, Rudie JD, Ghahremani D, et al. Altered functional connectivity in frontal lobe circuits is associated with variation in the autism risk gene CNTNAP2. Sci Transl Med 2010, 2: 56ra80.

158. Fox MD, Greicius M. Clinical applications of resting state functional connectivity. Front Syst Neurosci 2010, 4: 19.

159. Pereira F, Mitchell T, Botvinick M. Machine learning classifiers and fMRI: a tutorial overview. Neuroimage 2009, 45: S199-209.

160. Vapnik VN. The Nature of Statistical Learning Theory. New York: Springer, 1995.

161. Koshino H, Carpenter PA, Minshew NJ, Cherkassky VL, Keller TA, Just MA. Functional connectivity in an fMRI working memory task in high-functioning autism. Neuroimage 2005, 24: 810-821.

162. McAlonan GM, Daly E, Kumari V, Critchley HD, van Amelsvoort T, Suckling J, et al. Brain anatomy and sensorimotor gating in Asperger's syndrome. Brain 2002, 125: 1594-1606.

163. Davatzikos C, Fan Y, Wu X, Shen D, Resnick SM. Detection of prodromal Alzheimer's disease via pattern classification of magnetic resonance imaging. Neurobiol Aging 2008, 29: 514-523.

164. Guo Y, Wu G, Commander LA, Szary S, Jewells V, Lin W, et al. Segmenting hippocampus from infant brains by sparse patch matching with deep-learned features. Med Image Comput Comput Assist Interv 2014, 17: 308-315.

165. Zhang D, Wang Y, Zhou L, Yuan H, Shen D, Alzheimer's disease neuroimaging I. Multimodal classification of Alzheimer's disease and mild cognitive impairment. Neuroimage 2011, 55: 856-867.

166. Zhu D, Li K, Terry DP, Puente AN, Wang L, Shen D, et al. Connectome-scale assessments of structural and functional connectivity in MCI. Hum Brain Mapp 2014, 35: 2911-2923.

167. Haller S, Badoud S, Nguyen D, Garibotto V, Lovblad KO, Burkhard PR. Individual detection of patients with Parkinson disease using support vector machine analysis of diffusion tensor imaging data: initial results. AJNR Am J Neuroradiol 2012, 33: 2123-2128.

168. Pan S IS, Warwick K, Aziz TZ. Parkinson's disease tremor classification-a comparison between support vector machines and neural networks. Expert Syst Appl. 2012, 39: 10764-10771.

169. Smith DV, Clithero JA, Rorden C, Karnath HO. Decoding the anatomical network of spatial attention. Proc Natl Acad Sci USA 2013, 110: 1518-1523.

170. Zhang Y, Kimberg DY, Coslett HB, Schwartz MF, Wang Z. Multivariate lesion-symptom mapping using support vector regression. Hum Brain Mapp 2014, 35: 5861-5876.

171. Singh V, Mukherjee L, Chung MK. Cortical surface thickness as a classifier: boosting for autism classification. Med Image Comput Comput Assist Interv 2008, 11: 999-1007.

172. Ecker C, Rocha-Rego V, Johnston P, Mourao-Miranda J, Marquand A, Daly EM, et al. Investigating the predictive value of whole-brain structural MR scans in autism: a pattern classification approach. Neuroimage 2010, 49: 44-56.

173. Ecker C, Ginestet C, Feng Y, Johnston P, Lombardo MV, Lai MC, et al. Brain surface anatomy in adults with autism: the relationship between surface area, cortical thickness, and autistic symptoms. JAMA Psychiatry 2013, 70: 59-70. 
174. Jin Y, Wee CY, Shi F, Thung KH, Ni D, Yap PT, et al. Identification of infants at high-risk for autism spectrum disorder using multiparameter multiscale white matter connectivity networks. Hum Brain Mapp 2015, 36: 4880-4896.

175. Georgiades S Szatmari P, Boyle M. Importance of studying heterogeneity in autism. Neuropsychiatry 2013, 3: 123-125.

176. Di Martino A, Yan CG, Li Q, Denio E, Castellanos FX, Alaerts $\mathrm{K}$, et al. The autism brain imaging data exchange: towards a large-scale evaluation of the intrinsic brain architecture in autism. Mol Psychiatry 2014, 19: 659-667.
177. Di Martino A, Castellanos FX, Anderson J, Alaerts K, Assaf M, Behrmann Deen D, et al. The Autism Brain Imaging Data Exchange (ABIDE) Consortium: Open Sharing of Autism Resting State fMRI Data. Beijing: Human Brain Mapping Edition:18, 2012.

178. Fayed N, Modrego PJ. Comparative study of cerebral white matter in autism and attention-deficit/hyperactivity disorder by means of magnetic resonance spectroscopy. Acad Radiol 2005, 12: $566-569$. 